\title{
Efficacy of Lactobacillus fermentum Isolated from the Vagina of a Healthy Woman against Carbapenem-Resistant Klebsiella Infections In Vivo
}

\author{
Hanieh Tajdozian ${ }^{1,2 \dagger}$, Hoonhee $\mathrm{Seo}^{2 \dagger}$, Sukyung Kim², Md Abdur Rahim ${ }^{1,2}$, Saebim Lee ${ }^{2}$, and \\ Ho-Yeon Song ${ }^{1,2 *}$ \\ ${ }^{1}$ Department of Microbiology and Immunology, College of Medicine, Soonchunhyang University, Chungnam, \\ Cheonan 31151, Republic of Korea \\ ${ }^{2}$ Probiotics Microbiome Convergence Center, Chungnam, Asan 31538, Republic of Korea
}

\begin{abstract}
Carbapenem-resistant Enterobacteriaceae (CRE) that produce Klebsiella pneumoniae carbapenemase are increasingly reported worldwide and have become more and more resistant to nearly all antibiotics during the past decade. The emergence of $K$. pneumoniae strains with decreased susceptibility to carbapenems, which are used as a last resort treatment option, is a significant threat to hospitalized patients worldwide as $K$. pneumoniae infection is responsible for a high mortality rate in the elderly and immunodeficient individuals. This study used Lactobacillus fermentum as a candidate probiotic for treating CRE-related infections and investigated its effectiveness. We treated mice with $L$. fermentum originating from the vaginal fluid of a healthy Korean woman and evaluated the Lactobacilli's efficacy in preventive, treatment, nonestablishment, and colonization mouse model experiments. Compared to the control, pre-treatment with $L$. fermentum significantly reduced body weight loss in the mouse models, and all mice survived until the end of the study. The oral administration of $L$. fermentum after carbapenemresistant Klebsiella (CRK) infection decreased mortality and illness severity during a 2-week observation period and showed that it affects other strains of CRK bacteria. Also, the number of Klebsiella bacteria was decreased to below $5.5 \log _{10} \mathrm{CFU} / \mathrm{ml}$ following oral administration of $L$. fermentum in the colonization model. These findings demonstrate $L$. fermentum's antibacterial activity and its potential to treat CRE infection in the future.
\end{abstract}

Received: March 8, 2021 Accepted: August 23, 2021

First published online: August 25, 2021

*Corresponding author Phone: +82-41-570-2412 Fax: +82-41-570-2412 E-mail: songmic@sch.ac.kr

${ }^{\dagger}$ Hanieh Tajdozian and Hoonhee Seo contributed equally to this work.

Supplementary data for this paper are available on-line only at http://jmb.or.kr.

pISSN 1017-7825 eISSN 1738-8872

Copyright $@ 2021$ by the authors. Licensee KMB. This article is an open access article distributed under the terms and conditions of the Creative Commons Attribution (CC BY) license.
Keywords: Carbapenem-resistant Enterobacteriaceae, carbapenem-resistant Klebsiella, Lactobacillus fermentum, mouse model, mortality

\section{Introduction}

Probiotics are live microorganisms that can confer beneficial effects on the host when administered in adequate amounts [1-3]. It is important to understand that each probiotic strain independent of its genus and species has unique properties $[4,5]$. The Lactobacillus and Bifidobacterium genera have recently become the focus of many research pieces as two of the most frequently applied probiotics [6]. Some studies have demonstrated that Lactobacillus has antibacterial effects against carbapenem-resistant Enterobacteriaceae (CRE), Clostridium difficile, Escherichia coli, Shigella spp., Streptococcus mutans, Pseudomonas aeruginosa, and Staphylococcus aureus [7-11]. The main mechanisms reported for the antimicrobial activity of probiotic strains are: adhering to the intestinal surfaces to inhibit the adhesion of pathogens, competing for nutrients and inhibiting the growth of pathogens, modifying intestinal immune responses, and reducing the risk of infection [12-15].

Lactobacillus fermentum is one of the dominant Lactobacilli in a healthy woman's vaginal tract and intestine [16, 17]. Previous studies have defined L. fermentum as a possible probiotic candidate for protecting the intestine against pathogens and regulating microfloral balance $[18,19]$. L. fermentum can inhibit intestinal pathogen growth by producing inhibitory compounds including $\mathrm{H}_{2} \mathrm{O}_{2}$, bacteriocin, and biosurfactants and improve intestinal bacteria flora by reducing Clostridium perfringens [20-22]. Moreover, other studies have reported that L. fermentum shows probiotic potential against gram-negative bacteria, including E. coli, Salmonella Typhimurium, and Klebsiella pneumoniae biofilm [23, 24].

CRE are gram-negative bacteria that seriously threaten public health, and infections due to these organisms are associated with significant morbidity and mortality [25]. Carbapenemase (including new Delhi metallo- $\beta$ - 
lactamase (NDM), K. pneumoniae carbapenemase (KPC), and OXA-48) plays a major role in the antibioticresistant mechanism of CRE [26]. The increasing incidence of carbapenem-resistant K. pneumoniae (CRK) fundamentally alters the management of patients at risk of being colonized or infected by such microorganisms [27]. The crude mortality rate of diverse infections caused by CRK in patients ranges from $44 \%$ to $30.1 \%$ [28]. Moreover, invasive infections such as CRK bacteremia have shown striking crude and attributable mortality rates of $71.9 \%$ and $50 \%$, respectively $[28,29]$. At present, CRK is entirely resistant to all antibiotics, and there is no available drug to treat CRK infections [30]. Hence, there is an urgent need for a new drug candidate to produce antimicrobial drugs against CRK infections with improved efficacy.

Therefore, this study aimed to determine the in vivo antimicrobial activity of L. fermentum isolated from a healthy Korean woman's vaginal fluid for preventing and treating CRK intestinal infections by inhibiting the pathogens' growth and enhancing immunity in mouse models.

\section{Materials and Methods \\ Carbapenem-Resistant Klebsiella pneumoniae}

Clinical CRK isolates (SCHP191, SCHP192) were obtained from Soonchunhyang University Hospital Pathogenic Resource Bank and cultured in MacConkey broth (BD Difco, USA) at $37^{\circ} \mathrm{C}$ under aerobic conditions for $24 \mathrm{~h}$. The cultures were streaked onto MacConkey agar (BD Difco) plates containing $10 \mathrm{mg} / \mathrm{ml} \mathrm{imipenem}$ (Sigma-Aldrich, USA) and incubated at $30^{\circ} \mathrm{C}$ for $18 \mathrm{~h}$. The isolated colonies were transferred to MacConkey broth and cultured at $30^{\circ} \mathrm{C}$ for $18 \mathrm{~h}$. The bacterial culture $\left(\mathrm{OD}_{600}=1.0,2 \times 10^{9} \mathrm{CFU} / \mathrm{ml}\right)$ was stocked in sterile glycerol and kept at $-80^{\circ} \mathrm{C}$. Antimicrobial susceptibilities were determined using the standard broth dilution method according to the CLSI guideline. Minimum inhibitory concentrations (MICs) were $>1,025 \mathrm{mg} / \mathrm{l}$ for imipenem (Sigma-Aldrich), 1,025-512.5 mg/l for vancomycin (Sigma-Aldrich), 1,025-512.5 mg/l for kanamycin (SigmaAldrich), and $>1,025 \mathrm{mg} / \mathrm{l}$ for metronidazole (Sigma-Aldrich). In the CRK mice infection experiment, CRK (SCHP191) was used in models 1,2, and 4, and CRK (SCHP191) and CRK (SCHP192) were used in model 3.

\section{Isolation of Probiotics from Vaginal Samples}

A vaginal sample of a healthy woman was obtained from Soonchunhyang University Hospital and streaked onto MRS agar (BD Difco) plates followed by incubation at $30^{\circ} \mathrm{C}$ for $18 \mathrm{~h}$. The isolated colonies were cultured in MRS broth (BD Difco) at $37^{\circ} \mathrm{C}$ under aerobic conditions for $24 \mathrm{~h}$. The bacterial culture $\left(\mathrm{OD}_{600}=1.0,1 \times 10^{9} \mathrm{CFU} / \mathrm{ml}\right)$ was stored at $-80^{\circ} \mathrm{C}$ until use. Its $16 \mathrm{~S}$ rRNA gene sequence was analyzed in-depth using a commercial sequencing service (BIOFACT Co., Korea). This study was accomplished in the Probiotics Microbiome Research Center in Soonchunhyang University, Korea. Ethics approval was obtained from the Ethics Committee of Soonchunhyang University Hospital (eIRB) (IRB No. 2019-10-017-005).

\section{$16 S$ rRNA Gene Sequencing for Bacterial Identification}

The 16S ribosomal RNA gene was amplified by PCR using two universal 16S rRNA gene primers (27F, 5' -AGA GTT TGA TCC TGG CTC AG-3' / 1492R, 5'-GGT TAC CTT GTT ACG ACT T-3') [31]. The PCR was carried out at $95^{\circ} \mathrm{C}$ initial denaturation for $3 \mathrm{~min}$, followed by 30 cycles of $20 \mathrm{~s}$ at $95^{\circ} \mathrm{C}, 40 \mathrm{~s}$ at $56^{\circ} \mathrm{C}$ and $1 \mathrm{~min} 30 \mathrm{~s}$ at $72^{\circ} \mathrm{C}$, and a final extension at $72^{\circ} \mathrm{C}$ for $5 \mathrm{~min}$. The PCR product was purified using a PCR purification kit (BIOFACT Co., Korea) and sequenced with ABI PRISM 3730XL DNA Analyzer (Applied Biosystems, USA) using a BigDye Terminator v3.1 Cycle Sequencing Kit (Thermo Fisher Scientific, USA). Sequences were compared with the National Center for Biotechnology Information (NCBI) GenBank database using the Basic Local Alignment Search Tool (BLAST) search tool to find the closest matches.

\section{Ethics Committee and Experimental Animals}

All animal experiments in this study were reviewed and approved by the Institutional Animal Ethics Committee of Soonchunhyang University (Korea), following the committee's guidelines (SCH19-0053).

Nine-week-old specific pathogen-free (SPF) BALB/c female mice (Doo Yeol Biotech, Korea) were accommodated for one week before experiments. The mice were kept in individual cages with a $12 \mathrm{~h} / 12 \mathrm{~h}$ light/ dark cycle and relative humidity of 30 to $70 \%$ in an air-conditioned room $\left(23 \pm 2{ }^{\circ} \mathrm{C}\right)$. They were provided free access to food and water ad libitum.

Four mice models were included in this study, and mice were randomly divided into three groups $(n=5$ mice per group) for the experiments with models 1,2 , and 3 . They were divided into four groups ( $n=6$ mice per group) for the experiment with model 4 . The first and second mice models were used to evaluate the preventive potential and the curative effect, the third model for studying the effect of L. fermentum in a mouse model without the establishment of infection, and model 4 for determining the anti-infective activity of this strain in the colonization model. All animal experiments were performed per the World Health Organization recommendations in a biosafety level 2 facility (PMC animal room) at Soonchunhyang University.

\section{Study Design of in vivo L. fermentum Efficacy against CRK Multiple using Murine Infection Models}

For the mouse infection models, the mice received a $200 \mu$ l solution of $0.2 \mathrm{M} \mathrm{NaHCO}_{3}$ (Sigma-Aldrich) orally on day 2 in models 1,2, and 3 and on day 0 in model 4 to neutralize acidity and were challenged with CRK through the same route immediately after bicarbonate treatment. Cyclophosphamide (Sigma-Aldrich) at $450 \mathrm{mg} / \mathrm{kg}$ was administered intraperitoneally ( $200 \mu \mathrm{l} /$ mouse) for experiments in models 1,2 , and 3 , and a mixture of antibiotics (metronidazole, kanamycin, vancomycin each at a dose of $100 \mathrm{mg} / \mathrm{kg}$ ) was orally administered once a day (200 $\mu \mathrm{l} /$ mouse) for model 4 . Neutropenia was induced in models 1,2 , and 3 at 3 days before infection. The mice were 
induced with dysbiosis by administering the mixture of antibiotics on days -1 and -2 in model 4 . In models 1,2 , and 3, survival rates and illness severity scores were measured to determine the effect of $L$. fermentum for reducing CRK infection. For endpoint analysis, fecal samples were collected from individual mice on days 2 and 5 for models 1 and 2 and days 2, 5, 8, and 14 continuously for the model 4 experiment. CFU per gram of stool was determined by plating each sample onto MacConkey agar containing $10 \mu \mathrm{g} / \mathrm{ml}$ of imipenem $(\sim 100 \mathrm{mg}$ diluted in 1 $\mathrm{ml}$ of $\mathrm{NaCl}$ ). All experiments were repeated at least two times, and each experiment was performed under the same conditions.

\section{Preparation of Lactobacillus Strain for Treatment}

Briefly, the L. fermentum strain was cultivated in MRS broth at $37^{\circ} \mathrm{C}$ for $24 \mathrm{~h}$. The stock vial was as described previously. After culture, it was washed with distilled water, resuspended in saline, and adjusted to an approximate concentration of $1.6 \times 10^{9} \mathrm{CFU} / \mathrm{mice} / \mathrm{ml}$ for experiments in models 1,2 , and 3 and $9 \times 10^{9} \mathrm{CFU} / \mathrm{ml}$ in model 4 . The number and viability of the L. fermentum strain in saline after 1 week were determined by culturing it on MRS plates under aerobic conditions, followed by enumerating the colonies after $48 \mathrm{~h}$ of incubation. Mice in treatment groups received saline containing L. fermentum through drinking water and oral gavage in models 1 and 2 . They were administered only through drinking water in models 3 and 4 . Mice in the control groups for all experiments received only sterile saline in a similar manner instead of the lactobacillus suspension under the same conditions as those in lactobacillus-treated groups.

\section{Acute Oral Toxicity Studies}

For the acute toxicological studies, nine-week-old mice were randomly divided into two groups $(n=6$ mice per group) and treated with saline drinking water (control) and drinking water containing L. fermentum at the concentration of $1.4 \times 10^{10} \mathrm{CFU} / \mathrm{ml}$. Animals were observed for clinical signs, mortality, and body weights for 14 days following treatment. This study was performed according to the OECD Test Guidelines 423 with some modifications to test the acute oral toxicity of L. fermentum in the mouse models [32].

\section{CRK Mice Model 1 for Evaluating the Preventive Potential of $L$. fermentum}

The preventative effect of $L$. fermentum on BALB/c mice was examined. Briefly, $1.6 \times 10^{9} \mathrm{CFU} / \mathrm{ml} / \mathrm{mice}$ of L. fermentum in $100 \mathrm{ml}$ drinking water was given to the mice from 6 days before first CRK infection twice a week and was administered by oral gavage at a dose of $1.6 \times 10^{9} \mathrm{CFU} / \mathrm{mice} / 200 \mu \mathrm{l}$ on day 3 . Three days after neutropenia, infections were induced by oral administration of $200 \mu \mathrm{lCRK}$ at $1 \times 10^{10} \mathrm{CFU} / \mathrm{mice}$ on day 0 and $2 \times 10^{9} \mathrm{CFU} / \mathrm{mice}$ on day 2. Infected mice received bicarbonate treatment before the second infection administration on day 2 . To determine the number of viable CRK cells, stool samples were collected on days 2 and 5. MacConkey agar plates containing $10 \mu \mathrm{g} / \mathrm{ml}$ of imipenem were used to determine the number of viable CRK from serial dilutions of stool samples. The plates were incubated at $37^{\circ} \mathrm{C}$ aerobically for $24 \mathrm{~h}$. The results are expressed as $\log _{10}$. The number of $\mathrm{CFU}$ was expressed as CFU/ml. The mice were monitored for 2 weeks consecutively after the first infection for survival rate, severity of illness score, and weight.

CRK Mice Model 2 for Determining the Curative Effect of $L$. fermentum on CRK Lethal Sepsis

Mice were treated with $1.6 \times 10^{9} \mathrm{CFU} / \mathrm{ml} / \mathrm{mice}$ of $L$. fermentum in $100 \mathrm{ml}$ drinking water from days 1 to 8 twice a week and at a dose of $1.6 \times 10^{9} \mathrm{CFU} / \mathrm{mice} / 200 \mu \mathrm{l}$ on day 3 by oral gavage. Cyclophosphamide was injected on day -3 , and infection was induced using $200 \mu \mathrm{l}$ of the CRK suspension adjusted to $1 \times 10^{10} \mathrm{CFU} /$ mice on day 0 and $2 \times$ $10^{9} \mathrm{CFU} /$ mice on day 2 . Infected mice received bicarbonate treatment before the second infection administration on day 2. Stool samples were collected on days 2 and 5 , and $10 \mu \mathrm{l}$ aliquots of serially diluted stool samples were inoculated onto MacConkey agar plates containing $10 \mu \mathrm{g} / \mathrm{ml}$ imipenem. These plates were incubated at $37^{\circ} \mathrm{C}$ overnight under aerobic conditions. The number of CFU/gram of stool was determined and expressed as $\log _{10} \mathrm{CFU} / \mathrm{ml}$. Mice were observed for infection levels from day 0 until day 14 by measuring their body weights, recording their illness severity, and calculating their survival rate.

CRK Mice Model 3 for Determining the Effect of L. fermentum in a Murine Model without the Establishment of Infection

In this examination, two different strains of CRK were used to evaluate the effect of L. fermentum. For each strain, mice were injected with cyclophosphamide on day -3 and infected with $200 \mu \mathrm{l}$ of CRK suspension adjusted to $1 \times 10^{10} \mathrm{CFU} /$ mice on day 0 and $2 \times 10^{9} \mathrm{CFU} /$ mice on day 2 . Infected mice received bicarbonate treatment before second infection administration on day 2 . On day 0 , from $2 \mathrm{~h}$ after oral infection until day 10 , mice were treated with $1.6 \times 10^{9} \mathrm{CFU} / \mathrm{ml} /$ mouse of $L$. fermentum in $100 \mathrm{ml}$ drinking water. Subsequently, the mice's body weights were measured, and infection levels on days 1-10 were monitored by recording illness severity and mortality.

CRK Mice Model 4 for Determining the Anti-Infective Activity of L. fermentum in a Murine Model of Colonization

Mice received a single dose of a mixture of antibiotics (metronidazole, kanamycin, and vancomycin) on days -2 and -1 and were challenged by oral inoculation with $200 \mu \mathrm{l}$ inoculum of CRK at $1 \times 10^{9} \mathrm{CFU} / \mathrm{mice}$ on day 0 after receiving bicarbonate orally. The mice were treated with $9 \times 10^{9} \mathrm{CFU} / \mathrm{ml}$ of $L$. fermentum in $150 \mathrm{ml}$ drinking water twice a week for 2 weeks before CRK infection. To determine the CFU, serial dilution was performed, and a $10 \mu \mathrm{l}$ aliquot of each dilution was inoculated onto MacConkey agar plates containing $10 \mathrm{mg} / \mathrm{ml}$ imipenem. The plates 
were incubated at $37^{\circ} \mathrm{C}$ overnight. Stool samples were collected on days $2,5,8$, and 14 after oral infection, and the number of viable bacteria in the collected stool samples from mice was counted. Results are expressed as $\log _{10}$ $\mathrm{CFU} / \mathrm{ml}$

\section{Determination of $\mathrm{pH}$ in Fecal Samples during L. fermentum Treatment}

Nine-week-old BALB/c mice were divided into two groups ( $n=6$ mice in each group), one group received $L$. fermentum for 14 days, and the fecal $\mathrm{pH}$ was compared with the control group. The treatment group was given $100 \mathrm{ml}$ saline containing $6 \times 10^{9} \mathrm{CFU} / \mathrm{ml}$ of $L$. fermentum 3 times a week and was also administered twice a week using a zonde $\left(6 \times 10^{9} \mathrm{CFU} / 200 \mu \mathrm{l} / \mathrm{mice}\right)$. Control mice were exposed to saline like the treatment group. Fresh stool samples were collected before the start of L. fermentum treatment and on days 7, 11, and 14 after treatment. Each $100 \mathrm{mg}$ of stool was vortexed with $1 \mathrm{ml}$ of phosphate-buffered saline (PBS) and analyzed using an electronic $\mathrm{pH}$ meter (Mettler Toledo, Korea). This experiment was reviewed and approved by the Institutional Animal Ethics Committee of Soonchunhyang University (Asan, Korea) per the committee's guidelines (SCH21-0019).

\section{Statistical Analysis}

All data are presented as mean \pm SEM $\left(n^{1 / 45}\right)$. They were log-transformed for each experiment. The statistical difference in the number of microorganisms from different treatment groups was determined. $p<0.05$ was considered statistically significant.

\section{Results}

Identification and Acute Toxicity of the Isolated Lactobacillus Strain

The isolated vaginal L. fermentum was identified taxonomically by the robust $16 \mathrm{~S}$ rRNA gene sequencing (Table 1). For the acute toxicity assay, nine-week-old mice were treated with L. fermentum at dose levels based on the maximum achievable concentration. We recorded their mortality, general appearance, and body weights until day 14. There was no mortality or abnormality observed during the acute oral toxicity test (Fig. 1).

\section{Pre-Treatment with L. fermentum before CRK Infection in Mice}

Pre-treatment assay was performed to evaluate whether $L$. fermentum inhibited CRK infection (Fig. 2A). The pre-treatment results with $L$. fermentum showed that the mice treated with $1.6 \times 10^{9} \mathrm{CFU} / \mathrm{mice} / \mathrm{ml}$ of this strain before infection survived during the 14-day observation period (Fig. 2B). The sickness condition of mice was evaluated from day 0 until day 8. L. fermentum-treated mice showed a marked reduction in illness score compared to untreated mice $(p<0.001)$ (Fig. 2C). Additionally, untreated mice demonstrated significant body weight loss compared with that of the L. fermentum-treated mice $(p<0.05)$ (Fig. 2D). The preventative effect produced by $L$. fermentum on CRK infection in the mice was observed because $L$. fermentum significantly reduced CRK growth and decreased viable counts of CRK in stool samples to $3.2 \log _{10} \mathrm{CFU} / \mathrm{ml}$ at 5 days post-infection $(p<$ 0.001) (Fig. 2E). [Supplementary movie 1]

Table 1. Identification of the isolated $L$. fermentum bacterial strain based on 16S rRNA gene sequence analysis and its close relatives published in DNA databases.

\begin{tabular}{llcccc}
\hline NCBI reference & \multicolumn{1}{c}{ Organism } & Length & Score & Identities & Gaps \\
\hline NR_113335.1 & Lactobacillus fermentum strain NBRC 15885 & 1501 & 2752 bits (1490) & $1495 / 1498(99 \%)$ & $0 / 1498(0 \%)$ \\
NR_104927.1 & Lactobacillus fermentum strain CIP 102980 & 1502 & 2743 bits (1485) & $1487 / 1488(99 \%)$ & $0 / 1488(0 \%)$ \\
NR_118978.1 & Lactobacillus fermentum strain NCDO 1750 & 1381 & 2285 bits (1237) & $1320 / 1382(96 \%)$ & $11 / 1382(1 \%)$ \\
NR_029084.1 & Lactobacillus gastricus strain Kx156A7 & 1550 & 2410 bits (1305) & $1436 / 1500(96 \%)$ & $6 / 1500(0 \%)$ \\
NR_028810.1 & Lactobacillus ingluviei strain KR3 & 1506 & 2396 bits (1297) & $1434 / 1500(96 \%)$ & $9 / 1500(1 \%)$ \\
NR_041566.1 & Lactobacillus equigenerosi strain NRIC 0697 & 1519 & 2383 bits (1290) & $1420 / 1483(96 \%)$ & $9 / 1483(1 \%)$ \\
\hline
\end{tabular}

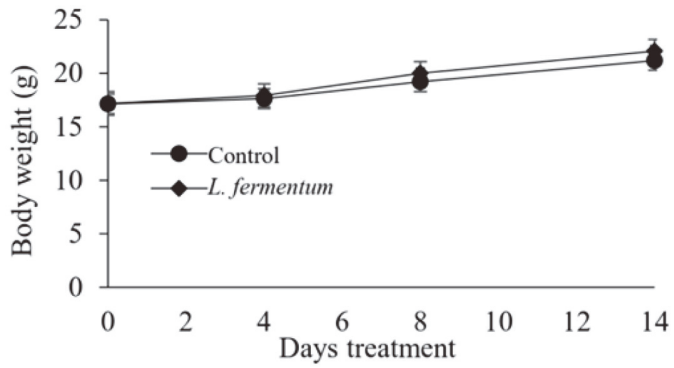

Fig. 1. Results of acute toxicity assay of probiotics. Nine-week-old BALB/c mice were treated with L. fermentum twice a week. Weights of mice were recorded for 2 weeks. 
A

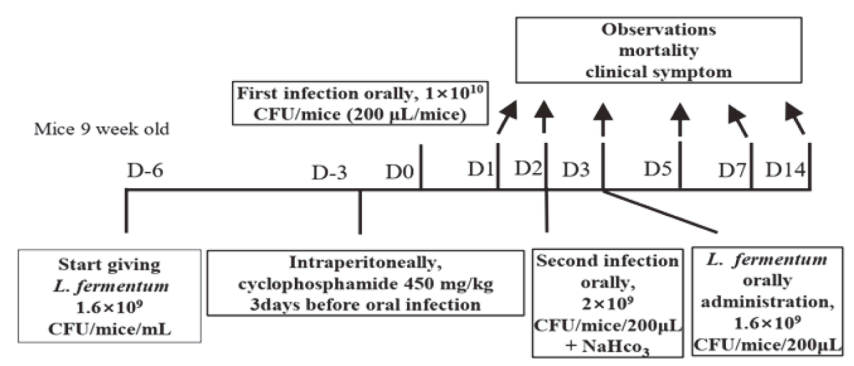

B

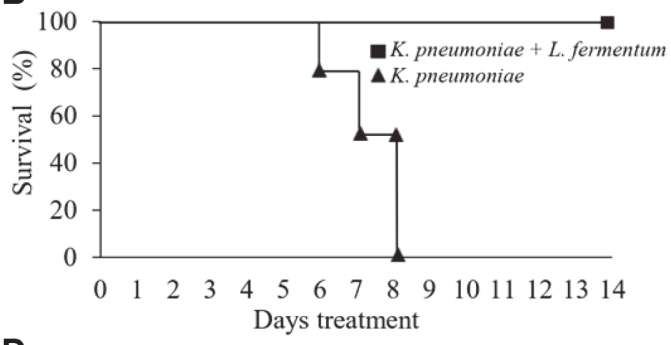

D

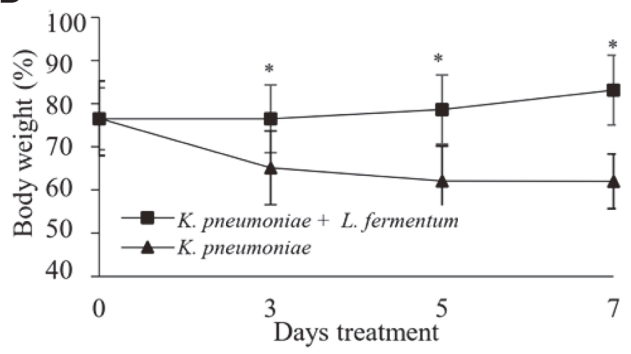

C

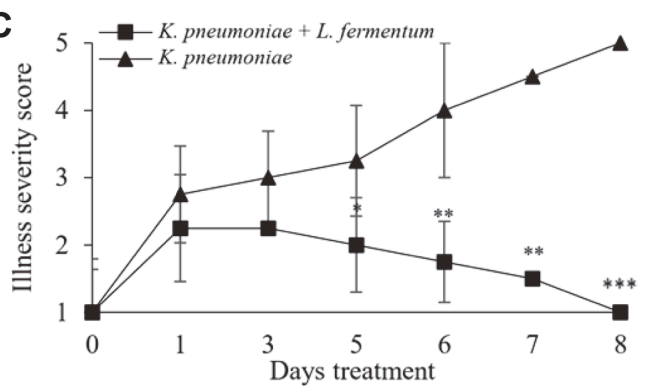

E

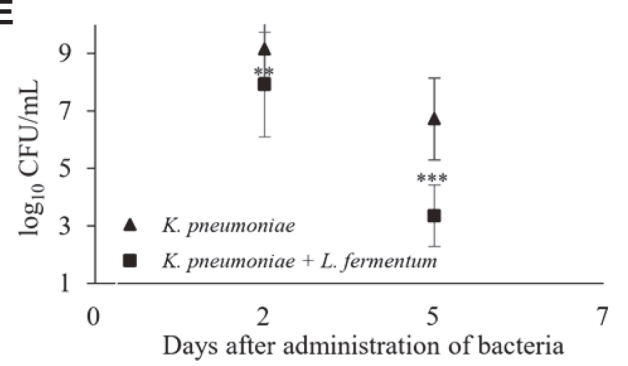

Fig. 2. Prophylactic effect of probiotics in a CRK-infected mouse model. (A) L.fermentum was administered 6 days before infection to confirm the preventive effect of probiotics. (B) The survival rate of the mice was observed for 2 weeks postinfection. (C) Illness severity score was evaluated during 8 days. (1, healthy; 2 , minimally ill; 3 , moderately ill; 4 , severely ill; 5 , dead). (D) Body weight was measured for 7 days. (E) Stool samples were collected from individual infected mice, and a CFU test for CRK was performed. Statistical significance with controls was analyzed using unpaired Student's $t$-test $\left({ }^{* * *} p<0.001 ;{ }^{* *} p<\right.$ $\left.0.01 ;{ }^{*} p<0.05\right)$.

\section{Therapeutic Efficacy of $L$. fermentum in a Murine Model of CRK}

The therapeutic effects of $L$. fermentum at a concentration of $1.6 \times 10^{9} \mathrm{CFU} / \mathrm{mice} / \mathrm{ml}$ on lethal CRK infections were evaluated in a mouse model (Fig. 3A). All mice infected with CRK in the untreated group died within 8 days after the first infection. In contrast, the survival rate was $75 \%$ for treated mice at 14 days post-infection (Fig. 3B). Untreated mice developed symptoms such as diarrhea and weakness after oral infection. Significant differences in illness scores between the treated and untreated groups were found from day 3 until day 8 ( $p<0.001$ ) (Fig. 3C). The untreated mice's body weights became lower than those of mice in the L. fermentum-treated group during the study. Untreated mice showed severe weight loss until the endpoint at 7 days after the first CRK infection $(p<0.05)$ (Fig. 3D). CRK viable counts decreased to $5.2 \log _{10} \mathrm{CFU} / \mathrm{ml}$ in the treated group stool samples, while the CRK growth rate remained high in the untreated group $(p<0.05)$ (Fig. 3E). [Supplementary movie 2]

\section{Antimicrobial Effect of L. fermentum in a Mouse Model without the Establishment of Infection}

To evaluate the treatment effect produced in the mouse model without the establishment of infection, L. fermentum at a concentration of $1.6 \times 10^{9} \mathrm{CFU} / \mathrm{mice} / \mathrm{ml}$ was given through drinking water at $2 \mathrm{~h}$ after CRK administration on day 0 (Fig. 4A). Treated mice survived until the end of the study. Untreated mice that received CRK strain 2 showed $50 \%$ mortality by day 8 , and all mice in the CRK strain 1 group died within 8 days (Fig. 4B). Mice in the untreated group showed higher scores of illness severity and disease symptoms, including weakness and diarrhea during the study, leading to significant differences between the treated and untreated groups $(p<$ 0.01) (Fig. 4C). L. fermentum reduced both illness severity and mortality in the treated group of each CRK strain. 
A

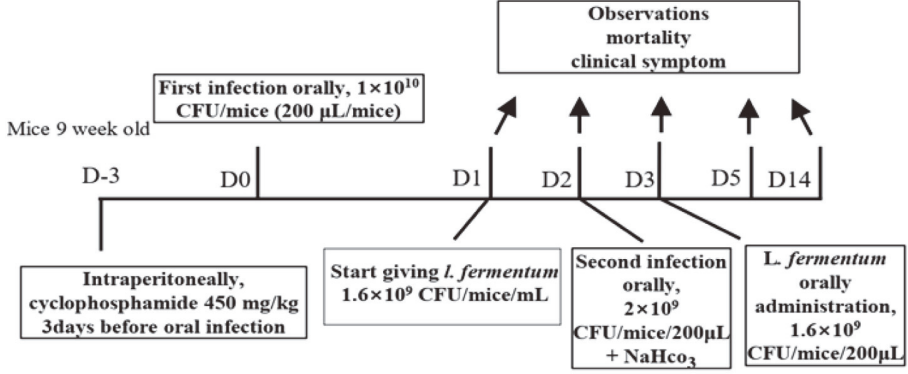

B

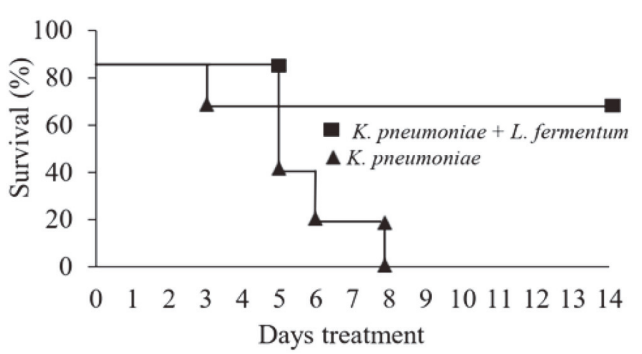

D

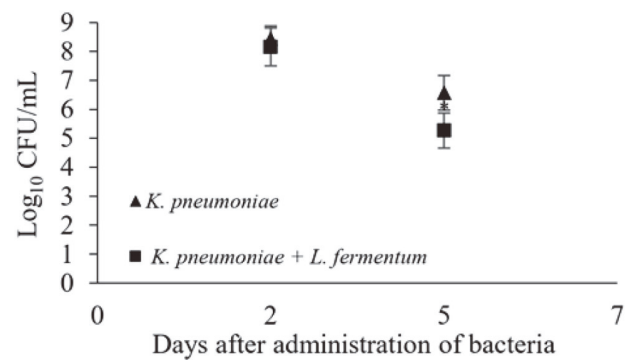

C

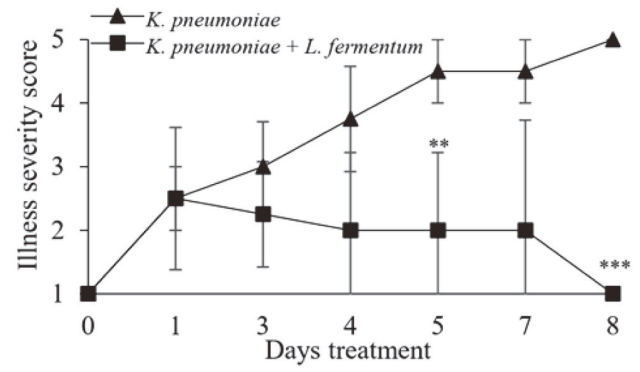

E

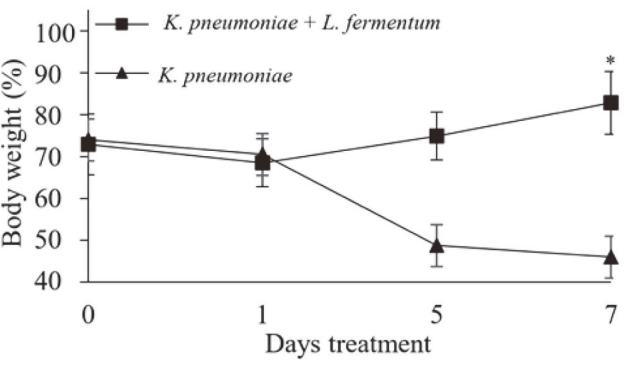

Fig. 3. Therapeutic effect of probiotics on CRK in an established infectious mouse model. (A) In order to evaluate the therapeutic effect of probiotics on CRK infection, probiotics treatment was started one day after clinical signs appeared after infection. (B) Survival rates, (C) Illness severity score, and (D) weight changes were observed or analyzed during probiotic treatment after infection. (E) Stool samples were collected from individual infected mice, and a CFU test for CRK was performed. Statistical significance with controls was analyzed using unpaired Student's $t$-test $\left({ }^{* *} p<0.001 ;{ }^{* *} p<0.01 ;{ }^{*} p<0.05\right)$.

\section{Effects of $L$. fermentum on Intestinal Colonization in a Murine Model}

Microbiological assessment of normal intestinal microflora in mice was performed by culturing uninfected mice fecal samples onto MacConkey agar plates containing $10 \mathrm{mg} / \mathrm{ml}$ imipenem during the study. No bacterial growth was observed on the agar plates after $24 \mathrm{~h}$ of incubation for all fecal samples. This result indicated an absence of CRE strains.

The colonization experiment showed that CRK has the ability to colonize the intestines of mice. Mice received L. fermentum at a $9 \times 10^{9} \mathrm{CFU} / \mathrm{ml}$ concentration before the CRK oral infection (Fig. 5A). The growth rate of CRK decreased in the group of mice treated with $L$. fermentum from after day 2 . The mice were monitored for 2 weeks, and CFUs were measured during the study. L. fermentum reduced viable counts to $5.2 \log _{10} \mathrm{CFU} / \mathrm{ml}$ in the treated group by day $14(p<0.01)$ (Fig. 5B). The numbers of CRK colonies were lower for stool samples of pre-treated mice than those in other groups until the end of the study. Therefore, there were significant differences in the CFU results between the pre-treated group (as a result of L. fermentum treatment) and the untreated group.

\section{Changes in $\mathrm{pH}$ of the Fecal Samples during L. fermentum Treatment}

To evaluate the effects of $L$. fermentum on fecal sample $\mathrm{pH}$ values, mice were treated with $L$. fermentum through oral gavage and drinking water. Before starting with L. fermentum treatment, the $\mathrm{pH}$ values were the same between the two groups and were found to be in the range of $6.9 \pm 0.2$. The $\mathrm{pH}$ values were determined in both the L. fermentum-treated and untreated groups on days 7,11 , and 14 . The $\mathrm{pH}$ of the fecal sample significantly decreased in the L. fermentum-treated group and became lower than those of mice in the untreated group $(p<$ 
A

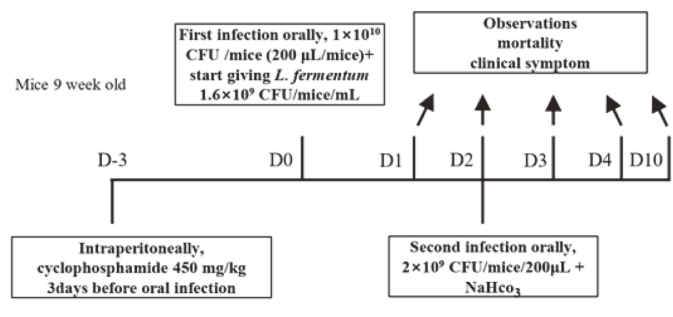

C

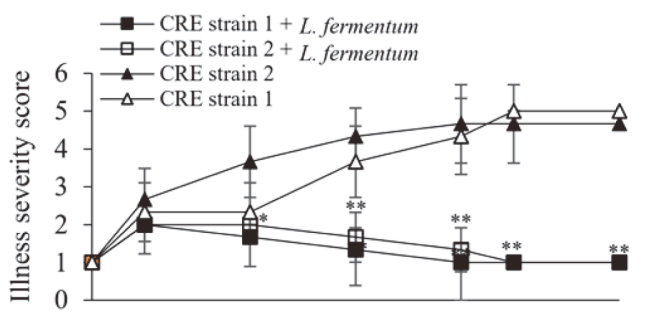

B

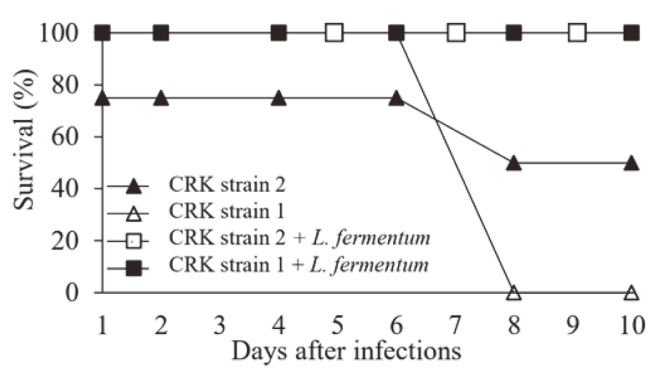

D

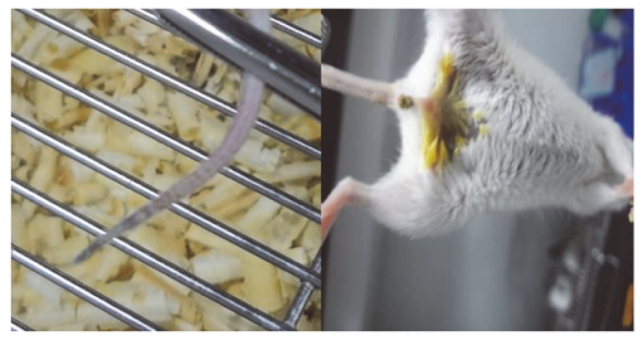

Fig. 4. Effect of probiotics in a non-established CRK infection mouse model. The effect of probiotics was evaluated in a mouse model in which CRK infection was not established. (B) Survival rates and (C) disease severity scores following probiotic treatment were evaluated for infection of two clinically isolated CRK strains. (D) All mice treated with probiotics were alive and healthy, whereas mice not treated with probiotics developed blood clots (left) and diarrhea (right) and even died. Statistical significance with controls was analyzed using unpaired Student's $t$-test $\left.\left({ }^{* *} p<0.01\right) ;{ }^{*} p<0.05\right)$.

A

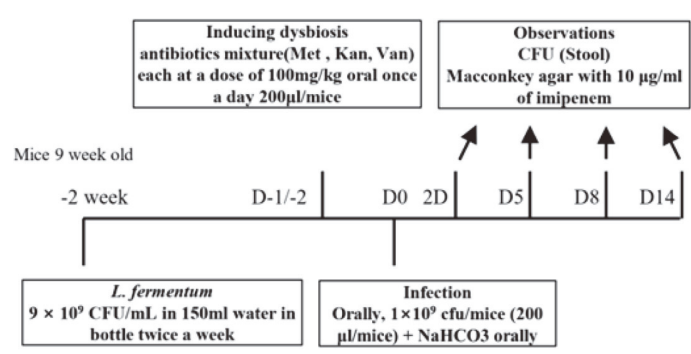

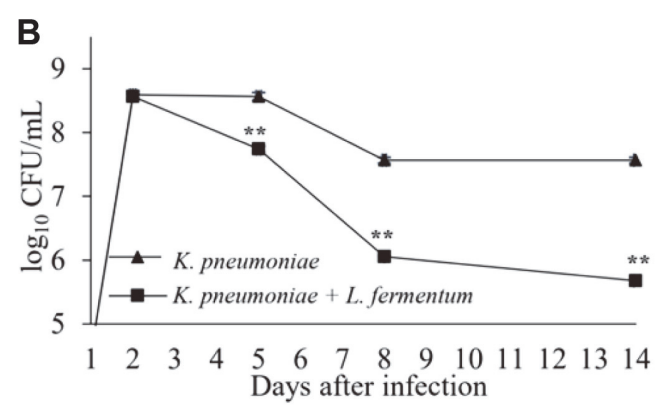

Fig. 5. Decolonization effect of probiotics on intestinal CRK. (A) The decolonization effect of CRK colonized in the intestines of probiotics was evaluated in a CRK infection model that did not lead to death. CRK was infected after administration of a mixture of antibiotics (Met, methicillin; Kan, kanamycin; Van, vancomycin) to induce intestinal colonization of CRK. (B) Stool samples were continuously collected on days 2, 5, 8, and 14 during the 14-day observation period after infection, and CFU tests for CRK were performed. Statistical significance with controls was analyzed using unpaired Student's $t$-test $\left({ }^{* *} p<0.01,{ }^{*} p<0.05\right)$.

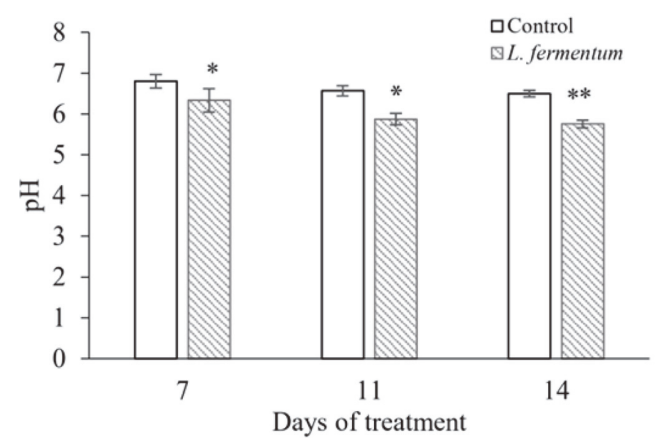

Fig. 6. Changes in stool $\mathrm{pH}$ following oral administration of $L$. fermentum in mice. The $\mathrm{pH}$ value of the stool was measured while $L$. fermentum was administered orally for 2 weeks, and it was statistically compared with the control group through the unpaired Student's $t$-test $\left({ }^{* *} p<0.01,{ }^{*} p<0.05\right)$. 
0.05) (Fig. 6A). The $\mathrm{pH}$ values were 6.80, 6.56, and 6.50 for the control group and 6.33, 5.87, and 5.75 in the L. fermentum-treatment group at days 7,11 , and 14 , respectively.

\section{Discussion}

Several experiments have shown that specific probiotic Lactobacillus spp. can inhibit intestinal infections by transit through the gastrointestinal tract, limiting the growth of pathogenic organisms and enhancing immunity [33-37]. Therefore, we expect probiotics to be used to solve antibiotic-resistant infections in the intestine by protecting it against pathogens. The main problem associated with antibiotic-resistant pathogens is the bacteria's resistance to all antibiotics used [38]. Nowadays, CRE is one of the more urgent threats and K. pneumoniae is on the rise among CRE pathogens that can cause infections at different body sites, including the intestine [39-42]. Also, K. pneumoniae, a typical bacterium of the intestinal flora and feces, can potently induce intestinal inflammation by irregularly increasing its number in the colon. Intestinal carriage of CRK is associated with a high risk of infection [43-48].

In this study, we explored the antimicrobial potential of many probiotics, but only L. fermentum isolated from the vagina of a healthy Korean woman showed more significant activity against CRK infection. Vaginal Lactobacillus strains with known antagonistic properties against bacteria modulate the vaginal microbiota by various mechanisms: auto-aggregation, production of lactic acid, hydrogen peroxide, bacteriocins, biosurfactants, coaggregation with pathogenic microorganisms, and adhesion to epithelial cells $[49,50]$. Several investigators have reported that $L$. fermentum is an antimicrobial probiotic that can reduce the risk of infection and has the ability to reduce concentrations of pro-inflammatory factors, ameliorate colon cells, and reduce TNF- $\alpha$ levels in in vivo experiments $[51,52]$. In vitro experiments have also shown that $L$. fermentum can co-aggregate with gastrointestinal pathogens and contribute to eliminating pathogens from the epithelia [53]. Other previous studies have also reported that whole cells of this L. fermentum and its acid supernatant exhibit an excellent ability to inhibit biofilm formation and Klebsiella growth. The acid supernatant of L. fermentum can also inhibit Klebsiella replication by producing high lactic acid and hydrogen peroxide levels. Thus, we evaluated this strain as a good candidate in this study.

In our view, L. fermentum might inhibit CRK, and the results of this study revealed the antimicrobial effect of L. fermentum against CRK. Several main findings were obtained by performing four different experiments using an infection model of mice in vivo.

Oral treatment with $L$. fermentum before infection markedly decreased illness severity and pathogenic infection induced in a mouse model and rescued mice from lethal CRK infections. Such observations indicate that Lactobacillus oral administration could stimulate the immune system to respond quickly to intestinal infections and support the potential preventive effects reported by recent studies of Lactobacillus against infections [54].

Throughout the evaluation of curative effects, a significant cure rate and a low peak illness severity score were observed for the L. fermentum-treated group, and the risk of mortality was also decreased for mice in the L. fermentum-treated group during the study period. Also, L. fermentum treatment showed a significant inhibitory effect against two different CRK strains in a non-establishment mouse model at only 8 days after CRK infection. Indeed, Lactobacillus treatment can possess a potent immunostimulatory effect to protect the host against $K$. pneumoniae infections and reduce such pathogen burdens based on previous reviews $[55,56]$.

According to previous studies, microbial gut overgrowth is hypothesized to be an important contributing factor to intestinal diseases [57]. To explore the Lactobacillus' effect against CRK more comprehensively, we established a colonization mouse model and collected fecal samples from 2 days after oral administration. This study assessed the effectiveness of treatment with L. fermentum and showed this strain's preventive ability against pathogenic intestinal colonization.

L. fermentum has been reported to increase organic acid and decrease $\mathrm{pH}$ in pig intestines [58]. In addition, administration of Bifidobacterium breve in mice increased organic acid concentration and decreased $\mathrm{pH}$, resulting in a decrease in methicillin-resistant S. aureus (MRSA) [59]. In this study, oral administration of L. fermentum reduced the number of CRK in the mouse intestine and showed low fecal $\mathrm{pH}$, suggesting a correlation between $L$. fermentum secretion of organic acids and their inhibitory effect on pathogens.

This study revealed that the L. fermentum strain possesses an excellent antimicrobial activity against CRK and characterized the strain's probiotic properties. In conclusion, a vaginal Lactobacillus of a healthy woman was found to be a good candidate for treating CRK infections in the future. However, further studies are needed to identify more potential candidates and determine the biological mechanisms involved in the antimicrobial effect of $L$. fermentum, the optimal dosing, and possible therapeutic side effects.

\section{Acknowledgments}

This research was financially supported by the Ministry of Trade, Industry, and Energy (MOTIE), Korea, under the "Regional Industry-based Organization Support Program" (Ref. No. P0001942) supervised by the Korea Institute for Advancement of Technology (KIAT). This study was also supported by the Soonchunhyang University Research Fund.

\section{Conflict of Interest}

The authors have no financial conflicts of interest to declare. 


\section{References}

1. Pineiro M, Stanton C. 2007. Probiotic bacteria: legislative framework-- requirements to evidence basis. J. Nutr. 137: 850s-853s.

2. Aoudia N, Rieu A, Briandet R, Deschamps J, Chluba J, Jego G, et al. 2016. Biofilms of Lactobacillus plantarum and Lactobacillus fermentum: Effect on stress responses, antagonistic effects on pathogen growth and immunomodulatory properties. Food Microbiol. 53: 51-59.

3. Sanders ME, Gibson G, Gill HS, Guarner F. 2007. Probiotics: their potential to impact human health. Council Agric. Sci. Technol. Issue Paper 36: 1-20.

4. Medina M, Izquierdo E, Ennahar S, Sanz Y. 2007. Differential immunomodulatory properties of Bifidobacterium logum strains: relevance to probiotic selection and clinical applications. Clin. Exp. Immunol. 150: 531-538.

5. Salminen S, Gueimonde M. 2004. Human studies on probiotics: what is scientifically proven. J. Food Sci. 69: M137-M140.

6. Falah F, Vasiee A, Behbahani BA, Yazdi FT, Moradi S, Mortazavi SA, et al. 2019. Evaluation of adherence and anti-infective properties of probiotic Lactobacillus fermentum strain 4-17 against Escherichia coli causing urinary tract infection in humans. Microb. Pathog. 131: $246-253$

7. McFarland LV. 2015. Probiotics for the primary and secondary prevention of $C$. difficile infections: a meta-analysis and systematic review. Antibiotics 4: 160-178.

8. Mirnejad R, Vahdati AR, Rashidiani J, Erfani M, Piranfar V. 2013. The antimicrobial effect of Lactobacillus casei culture supernatant against multiple drug resistant clinical isolates of Shigella sonnei and Shigella flexneri in vitro. Iranian Red Crescent Med. J. $15: 122$.

9. Kumar M, Dhaka P, Vijay D, Vergis J, Mohan V, Kumar A, et al. 2016. Antimicrobial effects of Lactobacillus plantarum and Lactobacillus acidophilus against multidrug-resistant enteroaggregative Escherichia coli. Int. J. Antimicrob. Agents 48: 265-270.

10. Ahn KB, Baik JE, Park O-J, Yun C-H, Han SH. 2018. Lactobacillus plantarum lipoteichoic acid inhibits biofilm formation of Streptococcus mutans. PLoS One 13: e0192694.

11. Chen C-C, Lai C-C, Huang H-L, Su Y-T, Chiu Y-H, Toh H-S, et al. 2020. Antimicrobial ability and mechanism analysis of Lactobacillus species against carbapenemase-producing Enterobacteriaceae. J. Microbiol. Immunol. Infect. 54: 447-456.

12. Girardin M, Seidman EG. 2011. Indications for the use of probiotics in gastrointestinal diseases. Dig. Dis. 29: 574-587.

13. Reid G, Burton J. 2002. Use of Lactobacillus to prevent infection by pathogenic bacteria. Microb. Infect. 4: 319-324.

14. Lebeer S, Vanderleyden J, De Keersmaecker SC. 2008. Genes and molecules of lactobacilli supporting probiotic action. Microbiol. Mol. Biol. Rev. 72: 728-764

15. Stöber H, Maier E, Schmidt H. 2010. Protective effects of Lactobacilli, Bifidobacteria and Staphylococci on the infection of cultured HT29 cells with different enterohemorrhagic Escherichia coli serotypes are strain-specific. Int. J. Food Microbiol. 144: 133-140.

16. Bao Y, Zhang Y, Zhang Y, Liu Y, Wang S, Dong X, et al. 2010. Screening of potential probiotic properties of Lactobacillus fermentum isolated from traditional dairy products. Food Control 21: 695-701.

17. Otero MC, Nader-Macías ME. 2006. Inhibition of Staphylococcus aureus by $\mathrm{H}_{2} \mathrm{O}_{2}$-producing Lactobacillus gasseri isolated from the vaginal tract of cattle. Anim. Reprod. Sci. 96: 35-46.

18. Gardiner GE, Heinemann C, Baroja ML, Bruce AW, Beuerman D, Madrenas Jn, et al. 2002. Oral administration of the probiotic combination Lactobacillus rhamnosus GR-1 and L. fermentum RC-14 for human intestinal applications. Int. Dairy J. 12: 191-196.

19. Reid G, Charbonneau D, Erb J, Kochanowski B, Beuerman D, Poehner R, et al. 2003. Oral use of Lactobacillus rhamnosus GR-1 and L. fermentum RC-14 significantly alters vaginal flora: randomized, placebo-controlled trial in 64 healthy women. FEMS Immunol. Med. Microbiol. 35: 131-134.

20. Anukam K, Reid G. 2007. Lactobacillus plantarum and Lactobacillus fermentum with probiotic potentials isolated from the vagina of healthy Nigerian women. Res. J. Microbiol. 2: 81-87.

21. Kaur B, Balgir P, Mittu B, Chauhan A, Kumar B. 2013. Purification and physicochemical characterization of anti-Gardnerella vaginalis bacteriocin HV6b produced by Lactobacillus fermentum isolate from human vaginal ecosystem. Am. J. Biochem. Mol. Biol. 3: $91-100$.

22. Shieh M-J, Shang H-f, Liao F-H, Zhu J-S, Chien Y-W. 2011. Lactobacillus fermentum improved intestinal bacteria flora by reducing Clostridium perfringens. E Spen Eur. E J. Clin. Nutr. Metab. 6: e59-e63.

23. Truusalu K, Mikelsaar R-H, Naaber P, Karki T, Kullisaar T, Zilmer M, et al. 2008. Eradication of Salmonella Typhimurium infection in a murine model of typhoid fever with the combination of probiotic Lactobacillus fermentum ME-3 and ofloxacin. BMC Microbiol. 8: 132 .

24. Al-Mathkhury HJ. 2012. Inhibitory effect of lactobacilli filtrate on Klebsiella pneumoniae biofilm. Iraqi Acad. Sci. J. 11: 168-179.

25. Logan LK, Weinstein RA. 2017. The epidemiology of carbapenem-resistant Enterobacteriaceae: the impact and evolution of a global menace. J. Infect. Dis. 215: S28-S36.

26. Chang P-C, Chen C-C, Lu YC, Lai C-C, Huang H-L, Chuang Y-C, et al. 2018. The impact of inoculum size on the activity of cefoperazone-sulbactam against multidrug resistant organisms. J. Microbiol. Immunol. Infect. 51: 207-213.

27. Petrosillo N, Giannella M, Lewis R, Viale P. 2013. Treatment of carbapenem-resistant Klebsiella pneumoniae: the state of the art. Exprt Rev. Anti-Infect. Ther. 11: 159-177.

28. Borer A, Saidel-Odes L, Eskira S, Nativ R, Riesenberg K, Livshiz-Riven I, et al. 2012. Risk factors for developing clinical infection with carbapenem-resistant Klebsiella pneumoniae in hospital patients initially only colonized with carbapenem-resistant K. pneumoniae. Am. J. Infect. Control 40: 421-425.

29. Borer A, Saidel-Odes L, Riesenberg K, Eskira S, Peled N, Nativ R, et al. 2009. Attributable mortality rate for carbapenem-resistant Klebsiella pneumoniae bacteremia. Infect. Control Hosp. Epidemiol. 30: 972-976.

30. Hamzan NI, Yean CY, Rahman RA, Hasan H, Rahman ZA. 2015. Detection of bla IMP4 and bla NDM1 harboring Klebsiella pneumoniae isolates in a university hospital in Malaysia. Emerg. Health Threats J. 8: 26011.

31. El-Mokhtar MA, Hassanein KM, Ahmed AS, Gad GF, Amin MM, Hassanein OF. 2020. Antagonistic activities of cell-free supernatants of lactobacilli against extended-spectrum $\beta$-lactamase producing Klebsiella pneumoniae and Pseudomonas aeruginosa. Infect. Drug Res. 13: 543.

32. Thumu SCR, Halami PM. 2020. In vivo safety assessment of Lactobacillus fermentum strains, evaluation of their cholesterol-lowering ability and intestinal microbial modulation. J. Sci. Food Agric. 100: 705-713.

33. Boris S, Barbés C. 2000. Role played by lactobacilli in controlling the population of vaginal pathogens. Microbes Infect. 2: 543-546.

34. Gill HS. 2003. Probiotics to enhance anti-infective defences in the gastrointestinal tract. Best Pract. Res. Clin. Gastroenterol. 17: $755-$ 773.

35. Bezkorovainy A. 2001. Probiotics: determinants of survival and growth in the gut. Am. J. Clin. Nutr. 73: 399s-405s.

36. Sullivan A, Nord CE. 2002. Probiotics in human infections. J. Antimicrob. Chemother. 50: 625-627.

37. Sullivan $\AA$, Nord C. 2002. The place of probiotics in human intestinal infections. Int. J. Antimicrob. Agents 20: 313-319.

38. Maldonado N, Silva de Ruiz C, Cecilia M, Nader-Macias M. 2007. A simple technique to detect Klebsiella biofilm-forming-strains. Inhibitory potential of Lactobacillus fermentum CRL 1058 whole cells and products. Commun. Curr. Res. Educ. Topics Trends Appl. Microbiol. 52-59. 
39. Lee BY, Bartsch SM, Wong KF, McKinnell JA, Slayton RB, Miller LG, et al. 2016. The potential trajectory of carbapenem-resistant Enterobacteriaceae, an emerging threat to health-care facilities, and the impact of the centers for disease control and prevention toolkit. Am. J. Epidemiol. 183: 471-479.

40. Choby JE, Howard-Anderson J, Weiss DS. 2020. Hypervirulent Klebsiella pneumoniae-clinical and molecular perspectives. J. Int. Med. 287: 283-300.

41. Caballero S, Carter R, Ke X, Sušac B, Leiner IM, Kim GJ, et al. 2015. Distinct but spatially overlapping intestinal niches for vancomycin-resistant Enterococcus faecium and carbapenem-resistant Klebsiella pneumoniae. PLoS Pathog. 11: e1005132.

42. Kesteman A-S, Perrin-Guyomard A, Laurentie M, Sanders P, Toutain P-L, Bousquet-Mélou A. 2010. Emergence of resistant Klebsiella pneumoniae in the intestinal tract during successful treatment of Klebsiella pneumoniae lung infection in rats. Antimicrob. Agents Chemother. 54: 2960-2964.

43. Wu T, Xu F, Su C, Li H, Lv N, Liu Y, et al. 2020. Alterations in the gut microbiome and cecal metabolome during Klebsiella pneumoniae-induced pneumosepsis. Front. Immunol. 11: 1331.

44. Lee I-A, Kim D-H. 2011. Klebsiella pneumoniae increases the risk of inflammation and colitis in a murine model of intestinal bowel disease. Scand. J. Gastroenterol. 46: 684-693.

45. Smith G, Blackwell C, Nuki G. 1997. Faecal flora in spondyloarthropathy. Br. J. Rheumatol. 36: 850-854

46. Schechner V, Kotlovsky T, Kazma M, Mishali H, Schwartz D, Navon-Venezia S, et al. 2013. Asymptomatic rectal carriage of blaKPC producing carbapenem-resistant Enterobacteriaceae: who is prone to become clinically infected? Clin. Microbiol. Infect. 19: 451-456.

47. Giani T, Tascini C, Arena F, Ciullo I, Conte V, Leonildi A, et al. 2012. Rapid detection of intestinal carriage of Klebsiella pneumoniae producing KPC carbapenemase during an outbreak. J. Hosp. Infect. 81: 119-122.

48. Qiao F, Huang W, Gao S, Cai L, Zhu S, Wei L, et al. 2020. Risk factor for intestinal carriage of carbapenem-resistant Acinetobacter baumannii and the impact on subsequent infection among patients in an intensive care unit: an observational study. BMJ Open 10: $\mathrm{e} 035893$.

49. Kang C-H, Kim Y, Han SH, Kim J-S, Paek N-S, So J-S. 2018. In vitro probiotic properties of vaginal Lactobacillus fermentum MG901 and Lactobacillus plantarum MG989 against Candida albicans. Eur. J. Obstet. Gynecol. Reprod. Biol. 228: 232-237.

50. Strus M, Kucharska A, Kukla G, Brzychczy-Włoch M, Maresz K, Heczko PB. 2005. The in vitro activity of vaginal Lactobacillus with probiotic properties against Candida. Infect. Dis. Obstet. Gynecol. 13: 280414.

51. Mikelsaar M, Zilmer M. 2009. Lactobacillus fermentum ME-3-an antimicrobial and antioxidative probiotic. Microb. Ecol. Health Dis. 21: $1-27$

52. Chen X, Zhao X, Wang H, Yang Z, Li J, Suo H. 2017. Prevent effects of Lactobacillus fermentum HY01 on dextran sulfate sodiuminduced colitis in mice. Nutrients 9: 545 .

53. Carmo MSd, Noronha FMF, Arruda MO, Costa ÊPdS, Bomfim MRQ, Monteiro AS, et al. 2016. Lactobacillus fermentum ATCC 23271 displays In vitro inhibitory activities against Candida spp. Front. Microbiol. 7: 1722.

54. Waki N, Kuwabara Y, Yoshikawa Y, Suganuma H, Koide H, Oku N, et al. 2017. Amelioration of Citrobacter rodentium proliferation in early stage of infection in mice by pretreatment with Lactobacillus brevis KB290 and verification using in vivo bioluminescence imaging. FEMS Microbiol. Lett. 364: fnw254.

55. Kamaladevi A, Balamurugan K. 2016. Lactobacillus casei triggers a TLR mediated RACK-1 dependent p38 MAPK pathway in Caenorhabditis elegans to resist Klebsiella pneumoniae infection. Food Funct. 7: 3211-3223.

56. Panpetch W, Chancharoenthana W, Bootdee K, Nilgate S, Finkelman M, Tumwasorn S, et al. 2018. Lactobacillus rhamnosus L34 attenuates gut translocation-induced bacterial sepsis in murine models of leaky gut. Infect. Immun. 86: e00700-17.

57. Lau HY, Huffnagle GB, Moore TA. 2008. Host and microbiota factors that control Klebsiella pneumoniae mucosal colonization in mice. Microbes Infect. 10: 1283-1290.

58. Liu H, Zhang J, Zhang S, Yang F, Thacker PA, Zhang G, et al. 2014. Oral administration of Lactobacillus fermentum I5007 favors intestinal development and alters the intestinal microbiota in formula-fed piglets. J. Agric. Food Chem. 62: 860-866.

59. Lkhagvadorj E, Nagata S, Wada M, Bian L, Wang C, Chiba Y, et al. 2010. Anti-infectious activity of synbiotics in a novel mouse model of methicillin-resistant Staphylococcus aureus infection. Microbiol. Immunol. 54: 265-275. 